\title{
Monitoring and Diagnostic of Transformer Solid Insulation
}

\author{
J. P. van Bolhuis, E. Gulski, and J. J. Smit, Member, IEEE
}

\begin{abstract}
Liberalization of the energy market has put increasing pressure on both electricity producers and distributors for lower costs. Since maintenance is a major expense account, such companies will be inclined to reduce maintenance budgets. At the same time, increased liability for non-delivered-energy increases the costs of sudden failure of a component. Transformers are such a component; they are often an essential link in the distribution network.

In order to reconcile both decreasing maintenance spending and reliable service, condition-based maintenance (CBM) is often proposed. The basis of a successful application of CBM lies in obtaining information on transformers, so that, on the one hand, a critical condition will be noted early enough to take measures and, on the other hand, so that only minimal maintenance is being applied to transformers still in good condition.

This paper will review a series of often mentioned techniques in order to assess what the value of this technique will be for CBM and whether it can be used for condition monitoring.
\end{abstract}

Index Terms-Condition monitoring, overview, solid insulation, transformer.

\section{INTRODUCTION}

$\mathbf{T}$ ODAY'S competitive market drives utilities more and more to the use of the available instead of the intended lifetime of a $\mathrm{HV}$ component. In principle, this option may be within the bounds of the conservative design of the HV construction, however, in the end it may be counteracted by long term aging processes of the electrical insulation system. A predisposition for such a failure mode can be very minor, e.g., a material irregularity introduced during manufacture. Due to its inactivity in the beginning of service life of a transformer, the defect passes detection for a long time, until operational stresses accelerate detrimental growth. Considering the damage that can be caused by a failing insulation system, it is important to develop diagnostic methods which recognize a so-called hidden fault as soon as its activity increases [1].

Today, utilities have to adapt to a lot of changing technical and economical requirements in industrialized countries [2], [3]. Deregulation measures have created an increasingly competitive working environment which has to lead to a more cost-effective power delivery system. Also, more high voltage installations have reached a service life of over 35 years, so the fraction of equipment in the terminative stage increases. Additionally, the preservation of maintenance expertise will become important in case the experts retire. The "aging wave" of the electrical infrastructure due to installation of numerous high voltage sub-

Manuscript received June 19, 2000; revised October 30, 2001.

The authors are with Delft University of Technology, Delft, The Netherlands (e-mail: j.p.vanbolhuis@its.tudelft.nl; vbolhuis@altavista.com)

Publisher Item Identifier S 0885-8977(02)02715-2.

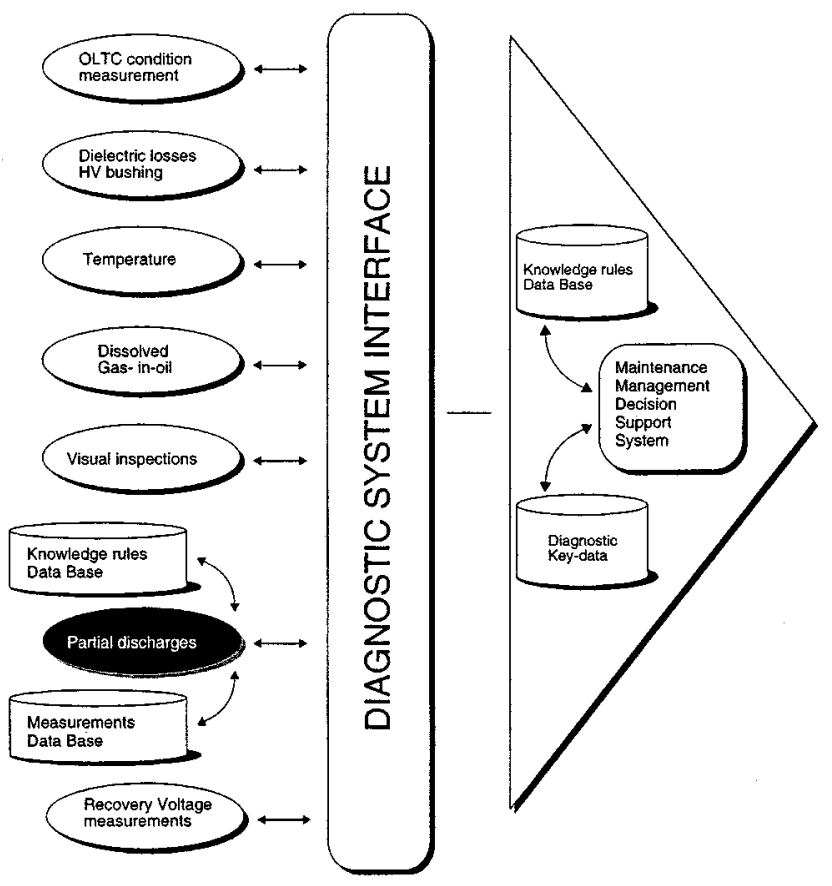

Fig. 1. Example of a diagnostic maintenance management system applied to maintenance of power transformers [4].

stations in the 1960s has its implications on the "unexpected" nonavailability of the electrical system. In general, the utilities are driven to redesign their maintenance approach by three primary factors:

- the need for cost reduction;

- lifetime extension;

- increasing liability awareness.

To meet these challenges, the electrical power branch in the Netherlands is now making the transition from the usual corrective (at failure) and time based strategies toward condition based maintenance. This need for condition based maintenance has encouraged the development of adaptable and cost-effective diagnostics. For HV transformers in addition to regular measurements like gas in oil analysis, several measuring tools have been introduced: dielectric measurements like RVM, relaxation current, tangens delta $(f)$, and partial discharge patterns [4] (Fig. 1).

\section{FACTORS INFLUENCING THE QUALITY OF TRANSFORMER INSULATION}

The aspects of aging in an electrical insulation system (EIS) have generated a lot of attention. The IEC TC 98 working group 


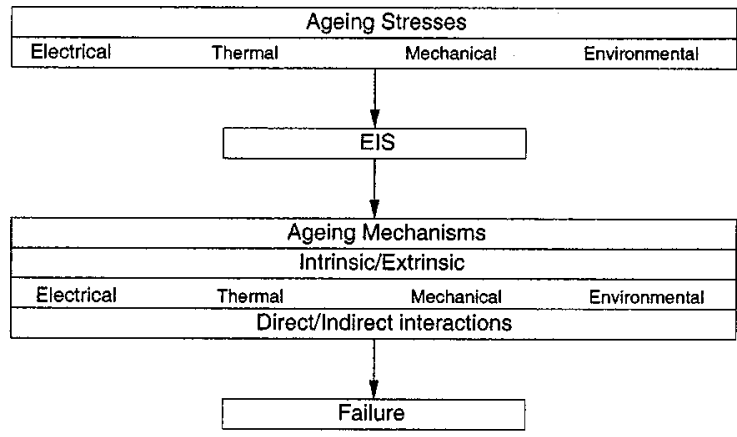

Fig. 2. Aging of an EIS [5].

is considering the evaluation of EIS and, in particular, the influence of aging upon EIS.

In Section II-A "General aspects of aging,"part of the approach of the TC 98 is given because the general aspects are also applicable to the EIS of transformers.

\section{A. General Aspects of Aging [5]}

The insulation system of a transformer consists mostly of oil and paper which are subject to aging. Aging is defined as the irreversible changes of the properties of an electrical insulation system (EIS) due to action of one or more factors of influence. Aging stresses may cause either intrinsic or extrinsic aging. In most EIS, extrinsic aging predominates because, in practice, they include imperfections and contaminants. A schematic representation of the basic process is shown in Fig. 2.

The type and level of contamination and/or the extent of imperfections in an EIS will significantly affect the service performance. In general, the fewer and less severe the contaminant and/or defects in the EIS, the better the performance of the equipment.

The aging factors produce electrical, thermal, mechanical, or environmental aging mechanisms that eventually lead to failure. During aging applied stresses, which initially may not affect the EIS, can come aging factors that, as a result, modify the rate of degradation.

When aging is dominated by one aging factor, this is referred to as single-factor aging. Multifactor aging occurs when more than one aging factor substantially affects the performance of the EIS. Aging factors may act synergistically, that is, there may be direct interactions between the stresses. Interaction may be positive or negative.

The aging of a practical EIS can be complex and failure is usually caused by a combination of aging mechanisms, even though there may be only one dominant aging factor [5] (see Figs. 3 and 4).

Based on the study as given in [5] for consideration of transformer insulation, the following factors are important.

1) Thermal Aging [5]: Thermal aging involves the progress of chemical and physical changes as a consequence of chemical degradation reactions, polymerization, depolymerization, diffusions, etc. It also involves the thermomechanical effects caused by the forces due to thermal expansion and/or contraction.

The rate of thermal aging and the aging caused by thermomechanical effects, as far as chemical reactions are concerned, are very much influenced by the operating temperature.

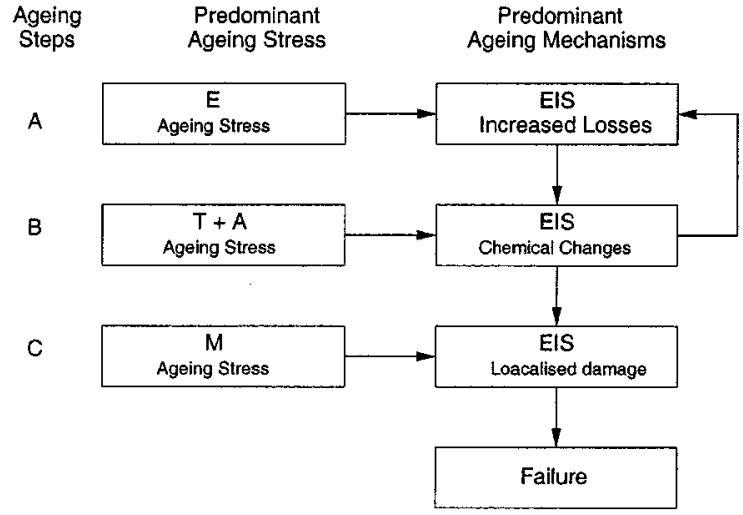

Fig. 3. Example of possible aging mechanisms as a function of time [5].

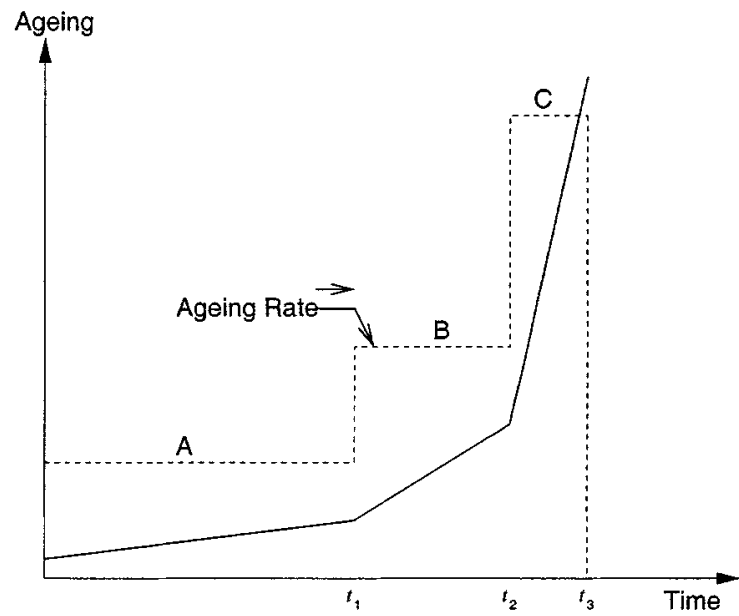

Fig. 4. Aging as a function of time for the example in Fig. 3 [5].

2) Electrical Aging [5]: Electrical aging, either AC, DC, or impulse, involves the following:

- the effects of partial discharges when the local field strength exceeds the breakdown strength in liquid or gaseous dielectric adjacent to, or included in, the EIS;

- the effects of tracking;

- the effects of treeing;

- the effects of electrolysis;

- the effects, related to those above, on the adjacent surfaces of two insulation materials where tangential fields of relatively high value may occur;

- the effects of increased temperatures produced by high dielectric losses;

- the effect of space charges.

Electrical aging is influenced by the field strength.

3) Mechanical Aging [5]: Mechanical aging involves the following:

- fatigue failure of insulation components caused by a large number of low-level stress cycles;

- thermomechanical effects caused by thermal expansion and or contraction;

- rupture of insulation by high levels of mechanical stress such as may be caused by external forces or operation condition of the equipment; 
- abrasive wear caused by relative motion between equipment components;

- insulation creep or flow under electrical, thermal, or mechanical stresses.

Mechanical aging is influenced by the rate of occurrence of repetitive mechanical stresses and the magnitude of nonrepetitive stresses.

4) Environmental Aging [5]: Environmental aging involves the chemical reaction processes mentioned under thermal aging. Environmental factors may also influence, in various ways, the kind and degree of degradation caused by other stresses to which an EIS is exposed. Other important aspects are the redistribution of stresses by changes in the environment and the influences of dust and other contamination on electrical behavior. At the present time there are no documented general rules for correlating the acceleration factors relating to environmental aging.

\section{B. Aging in the Transformer Insulation System}

1) Winding Insulation: Most windings in large power transformers consist of paper wrapped insulation on the windings. The paper is prepared from wood pulp and contains $90 \%$ cellulose. The latter is a natural polymer of glucose and consists of around 1200 monomer units once in its paper form. There is some destruction of the structure during manufacture, winding, and processing. Paper on a new transformer would start with an average chain length, in monomer units or degree of polymerization (DP) of around 1000. Laboratory experiments [6], [7] showed that over most of the aging range there is a linear relationship between time and the logarithm of the chain length. The aging rate is enhanced by increasing temperature, increasing moisture, and presence of air (oxygen) [8]. The strength of paper, in turn, is critically dependant upon the DP. For DPs of between 1000 and 500 the strength is virtually constant, but in the range 500 to 200 the strength is directly related to DP [6]. At a value of DP $=150$ and below, the strength is inadequate to withstand any winding movement [9]. The influence of temperature on the rate at which paper degrades is most commonly taken as Fabre and Pichon's ten degree rule-where the life halves for every $10^{\circ} \mathrm{C}$ increase in temperature [7]. The same workers [6], [7] showed that aging under air rather than vacuum introduces an additional acceleration factor of 2.5. The role of moisture is more complex. Water may enter the transformer from the outside, but it is also produced by the degradation process itself - the greater the degree of degradation, the greater the rate of moisture production. Dry paper may have a moisture content of $0.5 \%$; but the rate of degradation when the paper has $4 \%$ moisture is 20 times greater [10].

Some rating guides will use a $70^{\circ} \mathrm{C}, 40$ year life criterion and apply the $10^{\circ} \mathrm{C}$ rule to trade overload periods with times operating at less than $70^{\circ} \mathrm{C}$. The latter temperature relates to the rating ascribed to the design during a factory heat run. Since transmission units will generally operate at less than $70^{\circ} \mathrm{C}$ for most of their lives, a longer life before aging occurs can be expected than for generation units [10].

Experience in the U.K. [10], Australia [11], and the U.S. [12] indicates that even after 40 years of service the aging of transmission units is generally consistent with midlife. The excep-
TABLE I

SOME FAULTS With CORRESPONDING Key GASES

\begin{tabular}{l|l}
\hline Fault & Key gases produced \\
\hline \hline Hot spots (in oil) & Ethylene, hydrogen \\
\hline Hot spots (in cellulose) & $\mathrm{CO}, \mathrm{CO}_{2}$ \\
\hline Partial discharge & $\mathrm{H}_{2}, \mathrm{CH}_{4}$ \\
\hline Arcing & $\begin{array}{l}\mathrm{H}_{2} \text { and acetylene with in- } \\
\text { creasing temperature of } \\
\text { the fault location }\end{array}$ \\
\hline
\end{tabular}

tions arise where there have been hot spots at design specific areas. Early deterioration of the general winding insulation was found where moisture ingress had occurred. Reference [12] relates the relatively slight aging in 40 year old U.S. transformers but contrasts with 10 to 13 year old units where the oil had been allowed to sludge. Here, paper had reached DP values of 150 and the end of life. Therefore, for oil/paper systems, it is essential for designers and operators to maintain low moisture content.

2) Oil Insulation: The essential requirement for the oil is to maintain dielectric performance in the oil gaps and across solid surfaces, to age very slowly, and to have adequate thermal and viscosity properties to achieve factory heat run performance. A low quality oil, or one with a poor aging rate, is often associated with low transformer lives. The use of additives can allow a poorer oil to achieve adequate initial properties for performance. Hence, if used, the additive content must be monitored and maintained, since the loss of property values can be very rapid [10].

\section{MEASUREMENT TECHNIQUES}

This section will describe eight often used/mentioned diagnostic techniques for evaluating the transformer insulation. A short summary of the techniques, their status of development, field of application, and type of users can be found in Table II.

\section{A. Gas in Oil Analysis}

Dielectric oil [13] and solid cellulose dielectric materials will degrade and break down under thermal and electrical stresses. This process will produce gases in varying composition and in concentrations relating to the severity of the stresses applied to these materials. These gases will dissolve in the oil. The nature and concentrations of the gases sampled and analyzed are indicative of the type and severity of the fault in the transformer. The changes in the production of each gas and their rate of production are important factors in determining the type of fault(s) involved and of the evolution of the fault(s). Some specific gases are recognized as being indicative of certain types of faults.

Degradation of oil, be it due to overheating of the oil, partial discharge or arcing, will produce hydrogen, methane, ethane, ethylene, and acetylene. With each fault type, key gases are associated. The production of these gases and their rate of production are in direct relation to the materials involved, the temperature, and the energy released at the fault location.

Thermal degradation of oil-impregnated cellulose will produce carbon monoxide and carbon dioxide [13]. Table I and Fig. 5 show the key gases for several faults. 
TABLE II

Eight Often Used/Mentioned Measurement Techniques With Use, Developments, Status, and Application

\begin{tabular}{|c|c|c|c|c|c|}
\hline Method & Tests What & Status & Who uses it? & $\begin{array}{l}\text { Available for } \\
\text { monitoring }\end{array}$ & Literature \\
\hline$\overline{\mathrm{DGA}}$ & $\begin{array}{l}\text { Ageing of Oil and pa- } \\
\text { per, appearance of hot } \\
\text { spots and arcing or PD }\end{array}$ & $\begin{array}{l}\text { Widely used, much research } \\
\text { goes into refining the linking } \\
\text { of gases and causes }\end{array}$ & $\begin{array}{l}\text { Many utilities, many lab- } \\
\text { oratories are able to do a } \\
\text { DGA }\end{array}$ & Yes & [13] \\
\hline $\begin{array}{l}\text { Degree of Polymer- } \\
\text { ization }\end{array}$ & $\begin{array}{l}\text { Ageing of the insulat- } \\
\text { ing paper }\end{array}$ & $\begin{array}{l}\text { Relation of polymer chain } \\
\text { length and dielectric/ me- } \\
\text { chanic strength is known }\end{array}$ & $\begin{array}{l}\text { Mainly research labora- } \\
\text { tories as second opinion. } \\
\text { Not many utilities use it. }\end{array}$ & No & {$[10][14]$} \\
\hline Furfural & $\begin{array}{l}\text { Ageing of paper insula- } \\
\text { tion }\end{array}$ & $\begin{array}{l}\text { Under research, first appli- } \\
\text { cations in the field. There } \\
\text { are still unknowns in the be- } \\
\text { haviour of furfural in a trans- } \\
\text { former }\end{array}$ & Utilities, laboratories. & Yes & {$[8][14][15][16]$} \\
\hline$\overline{R V M}$ & $\begin{array}{l}\text { Water content of the } \\
\text { paper insulation, and } \\
\text { ageing of the paper in- } \\
\text { sulation }\end{array}$ & $\begin{array}{l}\text { Under research, some utilities } \\
\text { use it on a regular basis. }\end{array}$ & $\begin{array}{l}\text { Some utilities, laborato- } \\
\text { ries }\end{array}$ & No & $\begin{array}{l}{[16][17][18][19]} \\
{[20][21][22][23]} \\
{[24][25]}\end{array}$ \\
\hline Tangens delta & $\begin{array}{l}\text { Dielectric losses in the } \\
\text { insulation system }\end{array}$ & $\begin{array}{l}\text { Known, portable instruments } \\
\text { have been developed, an on- } \\
\text { line system that measures rel- } \\
\text { ative tangens delta for bush- } \\
\text { ings of a transformer is in use } \\
\text { in Australia }\end{array}$ & $\begin{array}{l}\text { Some utilities, and most } \\
\text { transformer producers, as } \\
\text { a quality control }\end{array}$ & $\begin{array}{l}\text { Relative Tangens } \\
\text { delta for bushings } \\
\text { of a transformer } \\
\text { can be measured } \\
\text { on-line. }\end{array}$ & {$[14][26][50]$} \\
\hline $\begin{array}{l}\text { Insulation Resis- } \\
\text { tance and polariza- } \\
\text { tion index }\end{array}$ & $\begin{array}{l}\text { Accumulation of polar- } \\
\text { izable material at insu- } \\
\text { lation interfaces. }\end{array}$ & Known & $\begin{array}{l}\text { Mainly utilities. } \\
\text { Can be used off line, on } \\
\text { site for periodic check }\end{array}$ & No & [14] \\
\hline Tangens Delta $(f)$ & $\begin{array}{l}\text { dielectric frequency re- } \\
\text { sponse, ageing of pa- } \\
\text { per, accumulation of } \\
\text { polarizable material in } \\
\text { the insulation system }\end{array}$ & $\begin{array}{l}\text { Instruments commercially } \\
\text { available, but much re- } \\
\text { search is being done on the } \\
\text { interpretation of the results }\end{array}$ & $\begin{array}{l}\text { Some Utilities, Laborato- } \\
\text { ries }\end{array}$ & No & {$[14][20]$} \\
\hline Partial Discharge & $\begin{array}{l}\text { Deterioration of the in- } \\
\text { sulation system, able } \\
\text { to detect some local- } \\
\text { ized defects }\end{array}$ & $\begin{array}{l}\text { Well known, research is be- } \\
\text { ing done on noise suppres- } \\
\text { sion, data interpretation and } \\
\text { on line use. }\end{array}$ & $\begin{array}{l}\text { Many utilities use it in } \\
\text { laboratories. PD level } \\
\text { measurement is part of } \\
\text { the commissioning test for } \\
\text { power transformers. } \\
\text { Some companies special- } \\
\text { ize in on-site or on-line } \\
\text { measurements using var- } \\
\text { ious methods: Filtering, } \\
\text { VHF, UHF, acoustical de- } \\
\text { tection }\end{array}$ & Yes & $\begin{array}{l}{[28][29][30][31]} \\
{[32][33][34][35]} \\
{[36][37][38][39]} \\
{[40][41][42][43]} \\
{[44][45][46][47]} \\
{[48]}\end{array}$ \\
\hline
\end{tabular}

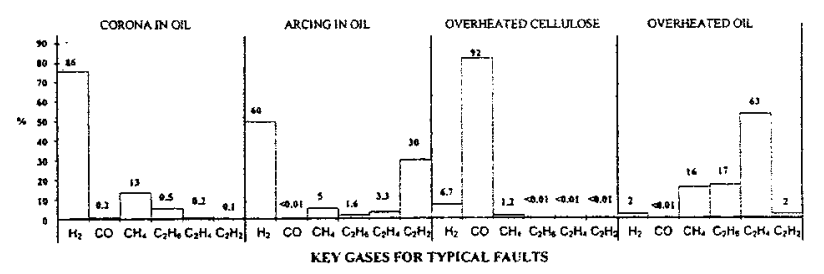

Fig. 5. Examples of key gases for typical faults.

Usually, an oil sample is taken collected from the transformer and analyzed using DGA.

The DGA is performed in the following three steps:

1) extraction of all the gases in the oil sample;

2) measurement of the quantity of each gas in the extracted gas;

3) calculation of the concentration of each gas in the oil sample.

The most commonly measured gases are: oxygen, nitrogen, hydrogen, carbon monoxide, carbon dioxide, methane, ethane, ethylene (or ethene), acetylene (or ethyne). Other extracted gases are sometimes analyzed, such as $\mathrm{C}_{3} \mathrm{H}_{8}, \mathrm{C}_{3} \mathrm{H}_{6}, \mathrm{C}_{3} \mathrm{H}_{4}$ refine a diagnostic. However this approach is not widely used.
Instead of taking periodical samples online, gas-in-oil monitors are commercially available that measure the concentration of nine different gases (hydrogen, methane, ethane, ethylene, acetylene, carbon monoxide, carbon dioxide, $\mathrm{C}_{3} \mathrm{H}_{8}$, and $\mathrm{C}_{3} \mathrm{H}_{6}$ ).

A high degree of success has been achieved in the area of determining a link between the following: 1) ratios of common fault gas concentration and specific fault types and 2) the evolution of individual fault gases and the nature and severity of the transformer fault.

The most commonly used gas-in-oil diagnostic methods include the following:

- IEEE C57.104-1991;

- Doernenburg;

- Rogers;

- IEC 599;

- Duval;

- GE.

\section{B. Degree of Polymerization}

The measurement of the degree of polymerization is intended to determine the condition of the paper winding insulation. Paper samples are taken from the transformer and the degree 


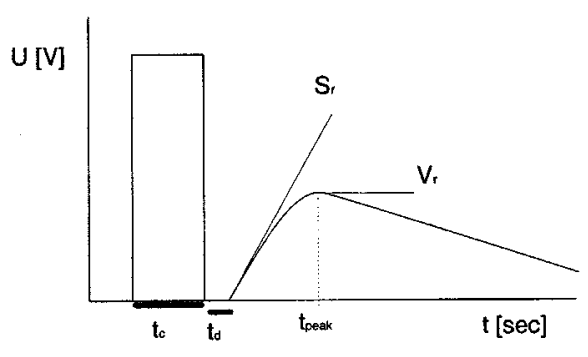

Fig. 6. Parameters for a recovery voltage measurement.

of polymerization, i.e., the average length of the cellulose chains, is determined by measuring the tensile strength of the samples [14]. New paper has an average chain length of 1000 [10] to 1500 [14]. After an extended period of service at high temperature in an oil with a high content of water and oxygen, the paper becomes brittle, changes color to brown, and its degree of polymerization falls to 150 [10], [14]. A drawback of this method is that, in order to take a paper sample, the transformer tank must be opened. Furthermore, there is no guarantee that the sample taken from a certain location of the paper winding is representative of the complete winding [14].

\section{Furfural}

Thermal degradation of cellulose paper also results in generation of furane $\left(\mathrm{C}_{4} \mathrm{H}_{4} \mathrm{O}-\mathrm{a}\right.$ colorless, water insoluble liquid) and various other furane derivates (for ease, furane and its derivates will be called furfural in the rest of this paper). Measurement of the furfural content of the oil can be used for a bulk measurement of the degree of polymerization of the paper insulation [8], [14], [15].

\section{Recovery Voltage Measurement (RVM)}

The rate of paper degradation depends on several parameters. The principal parameters are type of papers, pulp composition, thermal upgrading, moisture content, and temperature. The higher the water content of the paper, the higher the degradation rate. The RVM technique uses the dielectric response of the insulation to evaluate the condition of the insulation with respect to moisture content and aging [16]-[19].

The principle of RVM is shown in Fig. 6. First a sample is charged for a time $t_{c}$. Then, the sample is isolated from the HV source and short-circuited for a time $t_{d}\left(t_{c}>t_{d}\right)$. At the end of time $t_{d}$, the short-circuit is removed and the return voltage appearing at the electrodes can be measured. Three characteristic parameters of the return voltage can be defined. They are: the maximum of the return voltage $V_{r}$, the time at which the maximum is reached $t_{\text {peak }}$, and the initial slope of the return voltage $S_{r}[20]$.

By plotting the value for $V_{r}$ (and, additionally for $S_{r}$ and $t_{\text {peak }}$ ) for increasing charge time $t_{c}$ (with constant $t_{c} / t_{d}$ ) a polarization spectrum can be obtained.

The maximum in that polarization spectrum is called the dominant time constant.

The technique measures the dielectric polarization in oilpaper insulation. Impurities, such as moisture, aging products, etc., tend to collect at the interfaces between the components of

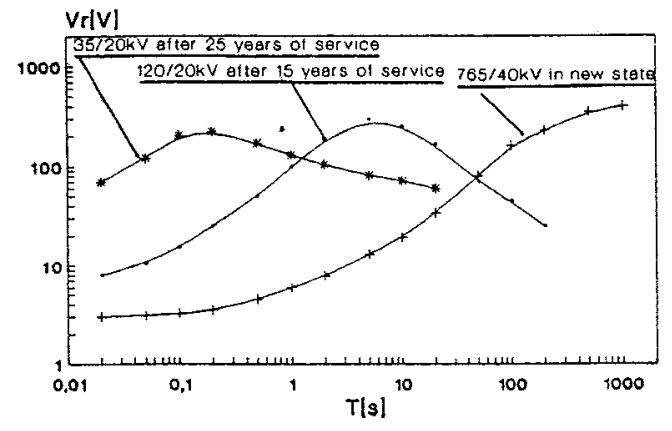

Fig. 7. RVM spectra for three transformers of different age [22].

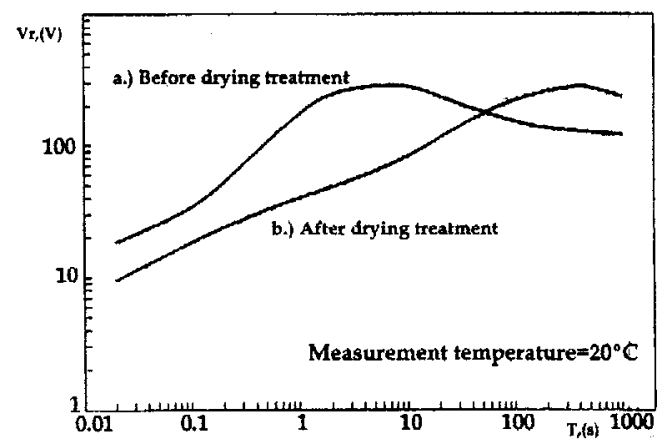

Fig. 8. Influence of moisture on the RVM spectrum [21].

the insulation and increase the electrical conductance at the interface. The increased conductivity in turn enhances interfacial polarization in the composite dielectric [16].

If the condition of the oil-paper insulation is homogeneous, that is, if the distribution of the temperature, moisture, aging byproducts, etc., in the insulation is uniform, the resulting curves have one dominant time constant, because the dominant time constant and the intensity of elementary polarization have uniform values (see Figs. 7 and 8) [21], [22].

A reciprocal method for measuring the polarization at interfaces is the relaxation current method [23], but the RVM method seems to be less influenced by disturbances, so may be better suited for application in the field [21], [24], [25].

\section{E. Tangens Delta}

The Tangens delta [14], [26] is a property of the electrical insulation system and a measure of the electrical losses in the insulation. Low values of tangens delta are usually required as proof of quality of the insulation. Sudden increases in value of tangens delta over time, are taken as a sign of deterioration of the insulation condition.

Portable instruments have been developed for field measurements of the tangens delta at a test voltage of 10 to $12 \mathrm{kV}$. The dielectric stress applied to the examined insulation during measurements at 10 to $12 \mathrm{kV}$ is much lower than the rated voltage, nevertheless, such measurements have gained popularity since they can be conveniently performed in a substation, and a comparison of readings taken on the same unit at regular time intervals effectively reveals a deterioration of the insulation dielectric properties [14]. 


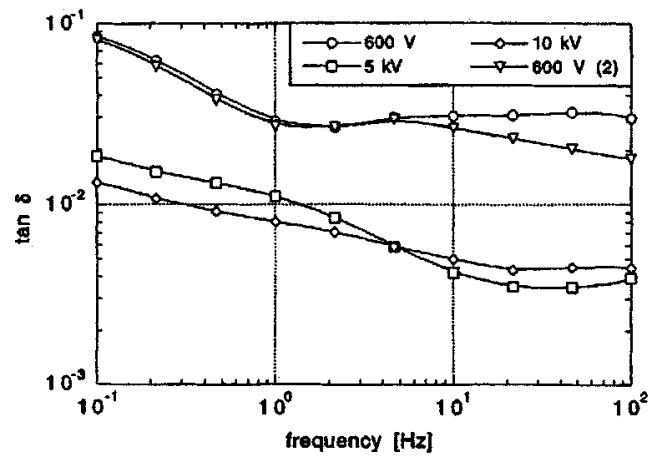

Fig. 9. Tangens delta $(f)$ measurement at different voltages on the insulation of a current transformer [20].

\section{F. Insulation Resistance Test and Polarization Index}

The insulation resistance test [26] [IEEE Std. 43-1974] is a useful indicator of contamination and moisture on the insulation surfaces of a winding. The insulation resistance is the ratio of the dc voltage applied between the winding copper and ground, to the resultant current. When a dc voltage is applied, three current components flow: a charging component into the capacitance of the winding, a polarization or absorption current involving various molecular mechanisms in the insulation, and a leakage component over the surface between exposed conductors and ground.

The polarization index is a variation on the dc insulation resistance test. The charging current, or indirectly the insulation resistance, is measured at two moments, often $15 \mathrm{~s}\left(R_{15}\right)$ and $60 \mathrm{~s}\left(R_{60}\right)$ after energizing the winding with the dc voltage. A ratio of $R_{60} / R_{15}<1.3$ indicates the presence of strongly polarizable material [14] (like water).

\section{G. Tangens Delta as Function of the Frequency}

This method measures the tangens delta as a function of the frequency of the test voltage [14], [20]. The tangens delta $(f)$ characteristic describes the spectrum of energy absorption by the dielectric. This spectrum has several poles, i.e., relaxation frequencies at which the applied signal reaches the frequency limit of polarization of certain molecules in the dielectric. An applied alternating voltage polarizes these molecules, which behave as dipoles. As the frequency of the applied field increases, some of the molecules cannot follow the imposed fast changes of polarity, and stop their participation in the polarization process. This is observed on the dielectric constant frequency characteristic $\epsilon_{r}=\Phi(f)$ which decreases with frequency in steps, corresponding to different molecules active in the respective frequency interval (Fig. 9) [14], [20].

The tangens delta $(f)$ spectrum (Fig. 9) has a complementary character, i.e., it shows resonant poles at each transition frequency from one step to another on the $\epsilon_{r}=\Phi(f)$ curve. An aging of the cellulose insulation has an influence on its polarization properties, which can be detected by an examination of the $\epsilon_{r}=\Phi(f)$ as well as the tangens delta $(f)$ characteristic.

In a simple form, this method has been implemented for several years. A special bridge measuring the insulation capacitance at $2 \mathrm{~Hz}$ and $50 \mathrm{~Hz}$ was developed to detect high water content in the insulation. A high ratio of $C_{2} / C_{50}>1.3$ indicated an excessive water content [14].

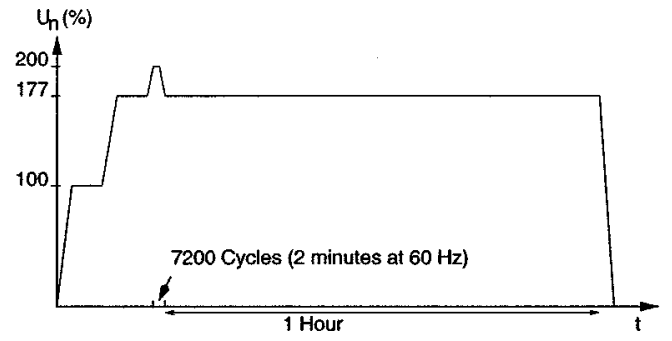

Fig. 10. Test voltage as a function of time during the induced voltage test.

Currently, much research toward applying this method toward paper insulation condition estimation is going on.

\section{H. Partial Discharge}

Partial discharge is an electrical phenomenon that occurs within a transformer whenever the voltage load is sufficient to produce ionization, and partially bridges the insulation between conductors. Although the magnitude of such discharges is usually small, they cause progressive deterioration and may lead ultimately to failure.

Each partial discharge occurring within the transformer produces an electrical pulse [28], [29], a mechanical pulse [29], [30], and TEM waves (radio) [31].

Several detection techniques exist for partial discharges. Conventional partial discharge detection, also called IEC 270 is suited for sensitive laboratory, but cannot easily be used in noisy environments, although research is being done toward noise suppression [32]-[35]. Nevertheless, important information about PD processes, PD patterns, and fault mechanisms can be obtained under laboratory conditions [36], [37], [39]. To apply all this experience under service conditions, the so-called VHF PD detection has been developed [40]. In contrast to the conventional method, it uses narrowband detection tuned to a frequency where an optimal signal/noise ratio can be found [29], [32], [41]-[43].

Acoustical detection can be used to locate the partial discharge source within the transformer [29], [30], [44]-[47]. Multiple sensors are placed on the tank of the transformer and by comparing propagation times of the partial discharges for each of the sensors, an estimated location for the PD source is generated.

In case of UHF PD detection (500-1000 MHz), an antenna is inserted in the transformer tank through an oil valve. The TEM waves generated by partial discharges are picked up by the antenna and a broadband filter is used to pick or select a suitable frequency area between 500 and $1000 \mathrm{MHz}$ [4], [31].

Important conclusions [1] are made regarding the insulation condition of power transformers based on a 1-h voltage- induced test (see [38], Fig. 10, and [48]). These HV apparatus are not discharge free and in general a discharge level $<500 \mathrm{pC}$ is tolerated. However, the interpretation of the measuring results may strongly depend on the opinions of the test engineers.

After the PD patterns of the test setup are localized and identified, PD patterns originating from the power transformer are recorded during the enhanced voltage test. Experiences show that in practice, two types of patterns are measured: 1) regular PD patterns, which are patterns that are characteristic for a 


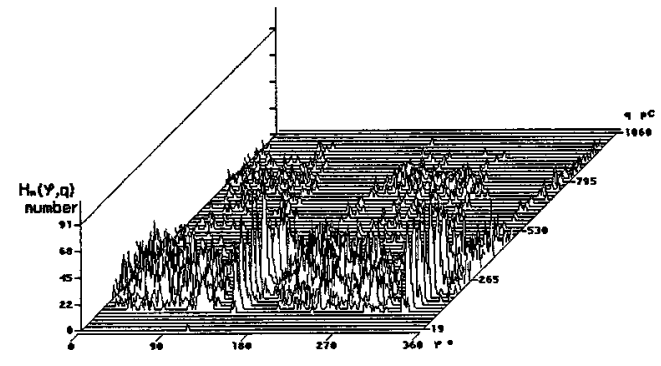

Fig. 11. Regular $H_{n}(\Phi, q)$ pattern as measured during off-line measurements on a 203-MVA transformer in good condition [37].

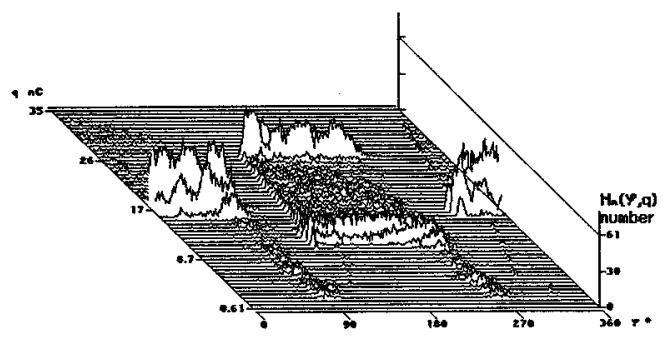

Fig. 12. Irregular $H_{n}(\Phi, q)$ pattern observed during off-line measurements on a 55-MVA reactor containing PD due to a damaged screen inside the test object [37].

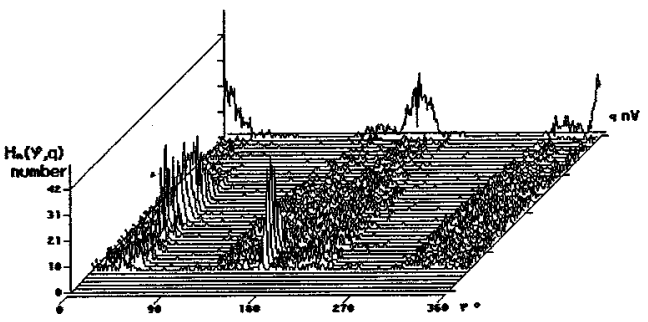

Fig. 13. $H_{n}(\Phi, q)$ pattern of a VHF measurement at $13 \mathrm{mHz}$ showing PD activity on phase $\mathrm{V}$ at $16 \mathrm{kV}$.

power transformer in good shape (see Fig. 11), and 2) irregular PD patterns, which are patterns that represent intolerable PD sources that can relate to insulation defects after manufacturing or aging effects during service life (see Fig. 12). When a large population of power transformers is available for testing, a PD database can be developed for classification of such defects in other transformers by their PD patterns [38]. Furthermore, such a PD database also provides information about general trends in regular and/or irregular PD patterns as they occur during induced voltage tests. This information may contribute to a clearer insight when assessing the insulation condition of power transformers and scheduling maintenance. As an illustration, Fig. 13 depicts an on-site PD measurement of the condition using the VHF-technique on a 50-kV/10-kV 14- MVA power transformer. The measurement shows a regular PD pattern, as can be concluded from comparison with the pattern in Fig. 11. No defects were found in the transformer [43].

\section{Special Aspects}

1) Furans and Moisture: The life expectancy of a high voltage transformer may be determined by the state of the insulation paper. Unfortunately, the insulation paper cannot easily be sampled from a working transformer, therefore,

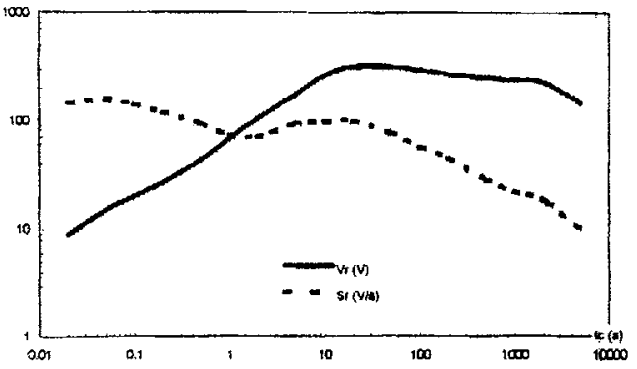

(a)

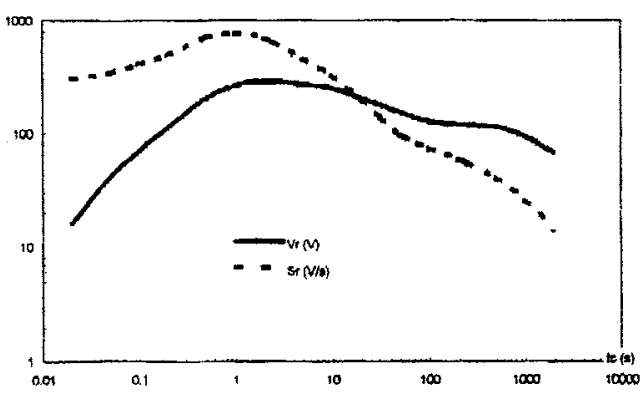

(b)

Fig. 14. RVM polarization spectra for two transformers of the same age. (a) Transformer 1. (b) Transformer 2 .

the degradation products of the paper dissolved in oil must be analyzed. Trace analysis of furanic compounds (further mentioned as furfural) can be done by high performance liquid chromatography using ultraviolet detection [8], [14], [15].

Furfural is known to be sensitive to degradation of paper, but little is known of its behavior in real transformers. Recent studies show that the furfural content of oil depends on the sampling location and on the time elapsed between degradation and sampling. Since furfural is hydrophilic (or at least some compounds) [opzoeken], it will tend to accumulate in humid paper. The amount of adsorbed furfural depends on the partition coefficients at given temperature and the humidity in the paper. At lower temperature, the absorption of furfural is higher and will be enhanced by a higher amount of absorbed water. One can assume that absorption and desorption processes occur simultaneously. Last but not least the decomposition of furfural will be a key factor which will influence the concentration of degradation products.

The distribution of degradation products between oil and paper is influenced by the $\log P$ value of the compounds and the moisture content of the paper. The moisture content of insulation paper can be inferred from the polarization spectrum measurement technique (RVM). The results [16] showed a significant improvement in diagnostic effectiveness by combining the singular furfural method with the RVM technique.

Fig. 14 shows the results of RVM tests performed on two different old transformers of the same type (Transformer 1 and Transformer 2). Transformers 1 and 2 had been in service for 36 years and had similar histories. They were selected to show the influence of moisture in paper on the furfural analysis. The polarization spectra of both units are relatively similar, indicating several elementary processes. Regarding these strongly inhomogeneous spectra, we can see that both units have aged insulation. The other important characteristic is the water content in 
the paper. As known the moisture in paper plays the dominant role, that is, the dominant time constant is strongly influenced by water content. Comparing the dominant time constants of these units with data from laboratory experiments, we can estimate the equivalent moisture content in unit 1 at about $2.3 \%$, in unit 2 over $3 \%$. The furfural analysis showed 0.14 ppm in Transformer 1. For Transformer 2, this value was below the detection limit of $0.01 \mathrm{ppm}$. If the RVM and furfural results are compared, it is clear that the RVM result is inconsistent with the furfural analysis. A possible explanation for this contradiction is as follows: if the water content in paper is high, the furfural is much more strongly adsorbed than if the paper is dryer. In this case there will be less furfural in the oil. The RVM method indicates that the water content in the paper in Transformer 1 is higher than in Transformer 2 [49]. For a more precise quantification of the influence of moisture on the furfural concentration in oil, more research is required.

\section{CONCLUSION}

In respect to solid insulation condition estimation, there currently are eight often used (mentioned) techniques, each with its own area of application and applicability. The techniques, their use, development, and applicability are mentioned in Table II.

Because of developments in microtechnology some methods are undergoing development that most certainly will improve the measurement and the corresponding interpretation of the insulation system behavior. For successful application of measurement results toward condition based maintenance, further research is needed, in corrobation with practical experience.

\section{REFERENCES}

[1] J. J. Smit, "High voltage insulation diagnosis for lifetime management," in Proc. ESEIM, Toyohashi, Japan, 1998, pp. 23-38.

[2] D. Kopejtkove et al., "Strategy for condition-based maintenance and updating of substations," in Proc. Cigré 23-105 Sess., 1996.

[3] J. J. Smit and C. M. Ackerman, "Diagnostic maintenance management system for MV and HV substations," in Proc. CIRED Conf., Birmingham, U.K., Paper 1.19.

[4] J. J. Smit et al., "Decision making experience with maintenance diagnosis of high voltage equipment," in Proc. Cigré 15-105 Sess. 1998.

[5] IEC Committee, "Evaluation and qualification of electrical insulation systems," IEC, Tech. Rep. 98/60 505/Ed. 2, 1998.

[6] D. H. Shroff and A. W. Stannett, "Review of paper aging in power transformers," Proc. Inst. Elect. Eng. C, vol. 132, no. 6, pp. 312-319, 1985.

[7] J. Fabre and A. Pichon, "Deteriorating processes and products of paper in oil," in Proc. Cigré Conf., 1960.

[8] E. Gockenbach and H. Borsi, "Grundlagen der diagnosemethoden an transformatoren vor ort," in Proc. Highvolt Koloquium Conf., 1997.

[9] R. Malewski, K. Feser, A. Claudi, and E. Gulski, "Digital techniques for quality control and in-service monitoring of HV power apparatus," in Proc. Cigré Conf., Padua, Italy, 1995.

[10] A. Wilson and P. N. Jarman, "Long term performance of transformer insulation," in Proc. INSUCON/ISOTEC 8th BEAME Int. EI Conf., 1998.

[11] D. M. Allan, "Practical life assessment technique for aged transformer insulation," Proc. Inst. Elect. Eng. A, vol. 140, no. 5, pp. 404-408, 1993.

[12] P. Griffin, L. Lewand, and B. Pahlavanpour, "Analysis of paper degradation byproducts as a tool for monitoring fault conditions in oil filled electric apparatus," in Proc. 62nd Doble Client Conf., 1995.

[13] C. Beauchemin and J.-P. Gebeault, "Tutorial: On-line monitoring of key fault gases in transformer oil: An operational experience accumulated over the years," in Proc. ISH, Montreal, QC, Canada, 1997.

[14] R. Malewski, "Continuous versus periodic diagnostics of HV power apparatus insulation," in Proc. ISH, Montreal, QC, Canada.
[15] Groupe d'action 15.01.3, "Analyze des composés furanniques: Un outil de maintenance prédictive de matériels electriques à huile fluide," Electra $\mathrm{nr} 175$.

[16] R. Brooks, "Reaction on question 11, preferred subject 2, group 15," in Proc. Cigré Conf., 1998.

[17] T. K. Saha, M. Darveniza, D. J. T. Hill, and T. T. Ie, "Electrical and chemical diagnostics of transformer insulation part A: Aged transformer samples," IEEE Trans. Power Delivery, vol. 12, pp. 1547-1554, Oct. 1997.

[18] V. der Houhanessian and W. S. Zaengl, "Time domain measurements of dielectric response in oil-paper insulation systems," in Proc. IEEE Int. Symp. EI, Montreal, QC, Canada, 1996.

[19] - "On-site diagnosis of power transformers by means of relaxation current measurements," in Proc. IEEE Int. Symp. EI, Arlington, VA, 1998.

[20] R. Neimanis, "Dielectric diagnostics of oil-paper insulated current transformers," Dept. Electr. Power Eng., Chalmers Univ. Technol., Göteborg, Sweden, Tech. Rep. 274L.

[21] R. Brooks, "Reaction on question 2 and 3, preferred subject 1, group 15," in Proc. Cigré Conf., 1998.

[22] Tettex Switzerland, "Polarizationsspektrumanlyze für eine isolierzustandsiagnostiek," Tettex, Switzerland, Tech. Rep. 096 062-DE-o.D.

[23] A. Helgeson and U. Gäfvert, "Calculation of the dielectric response function from recovery voltage measurements," in Proc. CEIDP, Virginia Beach, VA, 1995.

[24] U. Gäfvert, G. Frimpong, and J. Fuhr, "Modeling of dielectric measurements on power transformers," in Proc. Cigre, 1998, paper 15-103.

[25] S. M. Islam, P. R. S. Jota, and M. Stace, "Detection of oil-paper equilibrium moisture content in power transformers using hybrid intelligent interpretation of polarization spectrums from recovery voltage measurements," in Proc. IEEE Int. Symp. EI, Arlington, VA, 1998.

[26] MICAA Technical Help Index, Iris Power Eng., Etobicoke, ON, Canada.

[27] H. F. A. Verhaart, "A diagnostic to determine the condition of the contacts of the tap changer in a power transformer," in Proc. CIRED, Brussels, Belgium, 1995, paper 1.13.

[28] A. J. Kachler and H. Nieschwietz, "Broad and narrow band PD measurements on power transformers," in Proc. 5th ISH, Braunschwieg, Germany, 1987.

[29] J. Fuhr, "Analyze von TE-messungen an transformatoren im labor und vor ort," in Proc. Highvolt Kolloquium, 1997.

[30] Partial Discharge Source Location Using Three Dimensional Source Location Techniques, Physical Acoustics Corp., Princeton Junction, NJ.

[31] W. R. Rutgers and Y. H. Fu, "UHF PD detection in a power transformer," in Proc. 10th ISH, Montreal, QC, Canada.

[32] K. Feser, B. Feuchter, M. Lauersdorf, and T. Leibfried, "General trends in condition monitoring of electrical insulation,", Univ. Stuttgart, Fakultaet Elektrotechnik und Informationstechniek, Instut fuer Energieuebertragung und Hochspannungstechniek.

[33] K. Feser, U. Köpf, and M. Lauersdorf, "Probleme der TE-Messung vor Ort," ETG Fachbericht 56.

[34] B. Fruth, "Techniken für Teilentladungsmessungen an Hochspannungskomponenten im Betrieb," ETG Fachbericht 56.

[35] D. Wenzel, H. Borsi, and E. Gockenbach, "Unterdrückung Impulsförmiger Störsignale bei der vor-Ort-Teilentladungsmessung mit Hilfe der Naheste-Nachbar-Klassifikation," ETG Fachbericht 56.

[36] E. Gulski, H. P. Burger, A. Zielonka, and R. Brooks, "Classification of defects in HV components by fractal analysis of PD measurements," in Proc. CEIDP, San Francisco, CA.

[37] E. Gulski, H. P. Burger, G. H. Vaillancourt, and R. Brooks, "Digital tools for PD analysis during induced test of large power transformers," in Proc. CEIDP, San Francisco, CA.

[38] — "PD database for power transformers and reactors," in Proc. 10th ISH, Montreal, QC, Canada.

[39] H. P. Burger, E. Gulski, J. J. Smit, and R. Brooks, "Digital tools for PD analysis in three-phase transformers," in Proc. 10th ISH, Montreal, QC, Canada.

[40] K. Feser, "Trends in insulation monitoring of transformers," in Proc. 10th ISH, Montreal, QC, Canada.

[41] J. P. van Bolhuis, E. Gulski, and W. R. Rutgers, "Sensitivity discussion of different detection methods of partial discharges in a $50 / 10 \mathrm{kV}$ power transformer," Delft University of Technology, Delft, The Netherlands, Tech. Rep. TU-Delft/KEMA.

[42] N. H. Ahmed and N. N. Srinivas, "On-line partial discharge detection in transformer," in Proc. IEEE Int. Symp. EI, Arlington, VA, 1998.

[43] J. P. van Bolhuis, E. Gulski, J. J. Smit, T. Grun, and M. Turner, "Comparison of conventional and VHF partial discharge detection methods for power transformers," in Proc. 11th ISH, London, U.K. 
[44] P. M. Eleftherion, "Partial discharge XXI: Acoustic emission-based PD source location in transformers," IEEE EI Mag., vol. 11, Nov./Dec. 1995.

[45] A. A. Pollock, Practical Guide to Acoustic Emission Testing. Princeton Junction, NJ: Physical Acoustics Corp., 1988.

[46] J. Reason, "On-line transformer monitoring," Elect. World, Oct. 1995.

[47] R. Meunier and G. H. Vaillancourt, "Propagation behavior of acoustic discharge signals in oil-filled transformers," in Proc. 10th ISH, Montreal, QC, Canada.

[48] E. Gulski, H. P. Burger, G. H. Vaillancourt, and R. Brooks, "PD pattern analysis during induced test of large power transformers," IEEE Trans. Dielect. Elect. Insul., vol. 7, pp. 95-101, Feb. 2000.

[49] G. Csépes et al., "Correlation between electrical and chemical testing techniques for assessing degradation of oil-paper insulation," in Proc. Cigre, 1998, 15-202.

[50] D. Allan, E. Boyd, and D. Hinde, "A continuous insulation monitor for high voltage transformer bushings," in Proc. 7th ISH, Dresden, Germany.

J. P. van Bolhuis was born in Bangalore, India, on October 10, 1972. He received the M.S. degree in electrical engineering in insulation condition estimation on the basis of partial discharge behavior from Delft University of Technology, Delft, The Netherlands, in 1997. Currently, he is pursuing the Ph.D. degree in high-voltage engineering on the subject of transformer diagnosis and condition estimation from Delft University of Technology.

The focus of his attention lies with on-line partial discharge measurements and on-site dielectric measurements.
E. Gulski was born in Wloclawek, Poland in 1958. He received the M.S. degree in information technology from Dresden University of Technology, Dresden, Germany, and the Ph.D. degree from Delft University of Technology, Delft, The Netherlands, in 1982 and 1991, respectively.

From 1982 through 1986, he was a Research Assistant in the HV Laboratory at Dresden University of Technology. In 1987, he began research in the partial discharge diagnostics fields, relocating to the Delft University of Technology HV Laboratory. Currently, he is an Associate Professor involved in education and research in the field of insulation diagnosis of $\mathrm{HV}$ components.

Dr. Gulski is a member of different Cigré working groups and task forces.

J. J. Smit (M'98) was born in Dordrecht, the Netherlands, in 1949. He received the M.S. degree in experimental physics from the University of Amsterdam, Amsterdam, The Netherlands, and the Ph.D. degree from the State University of Leiden, Leiden, The Netherlands, in 1974 and 1979, respectively.

He was employed for 17 years at KEMA, Arnhem, Germany, where he became Section Manager within the transmission and distribution company. Since 1996, he has been a Professor in high-voltage technology at the Delft University of Technology, Delft, The Netherlands. Currently, his specific areas of interest are dc and ac HV materials, advanced diagnostics, and maintenance support systems.

Dr. Smit is a member of the Technical Committee of IEC'98 on Electrical Insulation Systems. In 1993, he became Secretary of the Cigré Study Committee 14, Materials for Technology, of which he is now Chairman. 